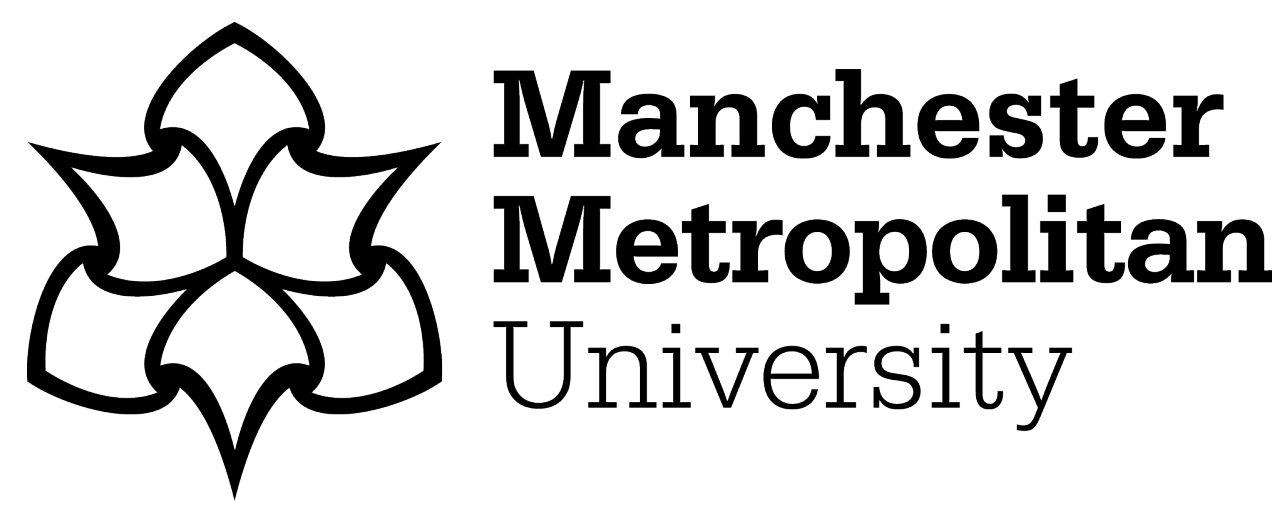

Jones, Rosie, Peters, Karen and Shields, Emily (2006) Providing for the next generation: adopting interactive whiteboards in information literacy training. In: Information Literacy: Recognising the Need, 17th May 2006, Staffordshire University, United Kingdom.

Downloaded from: https://e-space.mmu.ac.uk/8171/

Version: Accepted Version

Publisher: Chandos

Please cite the published version 


\section{Providing for the next generation: adopting interactive whiteboards in information literacy training.}

Rosie Jones: Senior Assistant Librarian, Learning Technologies (InfoSkills team). Aytoun Library, Manchester Metropolitan University, Manchester U.K.

Karen Peters: Senior Assistant Librarian, Information Skills (InfoSkills team). Aytoun Library, Manchester Metropolitan University, Manchester U.K.

Emily Shields: Deputy Library Services Manager (InfoSkills). Didsbury Library, Manchester Metropolitan University, Manchester U.K.

The importance of Information Literacy (IL) training has long been asserted in library literature. However, convincing students that they need such training remains a challenge. Research has shown that one way of demonstrating the relevance of IL is to embed it within students' courses and assessments. Yet in order for training to be effective, it is also crucial that students are engaged in the classroom and that they enjoy the learning experience. The Manchester Metropolitan University (MMU) Library InfoSkills team, established in June 2005, coordinates IL training across the library service and aims to ensure that the programme is delivered as effectively as possible. As part of this mandate, the team is currently investigating strategies for integrating new technologies into classroom teaching sessions as a means of enhancing the student learning experience through engaging and interactive IL delivery. This paper will focus on the use of Interactive Whiteboards (IWBs) in IL training and the success in adopting this new technology at MMU Library.

The adoption of IWBs as a teaching aid has been extensive in UK schools, but in higher education (HE) this implementation has not been so widespread, with the main usage being in teacher training departments (Becta, 2003; TechLearn, no date). Little has been written regarding the use of IWBs in HE. Although their installation at MMU has been extensive and they form part of the standard kit in MMU's technology-enhanced teaching rooms, in the majority of cases they are used merely as glorified projection screens. Yet, according to JISC: "Studies have found [IWBS] to be highly motivating and learner-centred when integrated innovatively. They offer a powerful facility for 
integrating media elements into teaching to enhance content and support collaborative learning" (TechLearn, no date, p.6). As an increasing number of schools adopt whiteboard technology, there is a growing possibility that students arriving in HE have been taught with them. Hence, with greater student expectations and the potential for IWBs to transform teaching, by making it interactive, visual and motivating, IWB uptake in HE is crucial.

The MMU Library Service quickly recognised the importance of IWBs in terms of IL training and was keen to integrate this technology into its teaching. This has been highlighted by the purchase of IWBs for each of MMU's seven site libraries. There are two key reasons for the library's rapid response to this technology. Firstly, research shows that "learning is optimal when it is an active process" (Philip and Schmidt, 2004); IWBs provide an easy form of interactivity which should stimulate and engage an audience. Secondly, adopting and using IWBs to their full potential allows the library to not only enhance training experiences but also to impress both the student and the academic. They have seen that the library is at the forefront of technology adoption and this in turn has raised the profile and the status of the library in the university. The IWB has the ability to transform IL training at MMU Library even further, whilst establishing the library as forerunners in this new teaching development within the academic community.

IWBs have changed InfoSkills provision greatly as they have allowed a level of participation in training sessions that was not previously possible. Used in conjunction with the specialist software (ACTIVstudio 2$)^{1}$ they allow trainers to pre-prepare flipcharts (similar to PowerPoint slides) or to annotate over any application that is currently running. MMU Library is also piloting an audience participation voting system (ACTIVote) ${ }^{1}$ as part of this software which allows the trainer to conduct votes throughout the session. This keeps the event interactive and allows the trainer to assess if key concepts have been understood by the audience. Perhaps most importantly, research has shown

\footnotetext{
${ }^{1}$ For more information on ACTIVstudio and ACTIVote see The Promethean Centre of Excellence at: http://www.ioe.mmu.ac.uk/promethean/
} 
that IWBs are able to support a range of learning styles and intelligences (Promethean Ltd., 2004) which is the fundamental aim of any successful training session.

ACTIVstudio functions have been utilised in MMU InfoSkills sessions in the following ways:

- Using flipcharts to write up keywords from a search query, allowing interaction as students shout out the answers

- Highlighting areas in a PowerPoint presentation or on a website

- Using the timer facility to ensure that set exercises run to time

- Using ACTIVote for knowledge checks and evaluation

- Using ACTIVote to break up lectures and engage the audience

Since IWBs have been used in InfoSkills sessions the benefits to the Library and the students have been sizeable. Library staff are conscious that the sessions they are running are far more interesting and interactive for the students and as a result the sessions are relaxed and enjoyable for both trainers and participants. Staff who use the boards regularly have stated that they would "hate to go back to the old style projection units" (staff feedback form) as the boards allow more movement around the room to highlight important areas of a database and offer more chances to engage the audience.

Feedback from students and academics has been equally positive. On evaluation forms students highlight the interaction of the sessions and several have mentioned the IWB as a specific reason for their enjoyment of the session:

"Very clear and interactive so time flew by!"

"[l enjoyed the] Demo on IWB"

"The demonstration on the IWB was really useful"

"It was great seeing the IWB used to its full potential" Although tutor feedback is more anecdotal, a number of librarians have received positive comments from academics on the use of the IWB as a training tool. In fact, some library staff have even been asked to provide 
training for academics in the use of IWBs. Academics have been impressed by the library's use of them and this has heightened their view of the library as a forward thinking service.

The library's investment in IWBs has led to a need to train library staff to ensure that IWBs are used to their full potential. In December 2005, the Training and Development Librarian and the InfoSkills team ran an "Introduction to Interactive Whiteboards" training day. The aim was to introduce staff to the IWBs, show them a range of the boards' functions and illustrate various ways to use the boards in library training sessions. The day began with training delivered by an instructor from Promethean ${ }^{2}$ and was followed by hands-on small group workshops led by InfoSkills team members. These workshops highlighted features of IWBs that are particularly suited to InfoSkills training and involved participants in a variety of games and other whiteboard activities, encouraging them to have fun whilst using the technology in a practical way. The InfoSkills team felt it was crucial that staff enjoyed using the boards and that they gained useful experience within a comfortable environment so that they would be confident when subsequently integrating IWBs into their future teaching.

Due to limited space only key members of staff who deliver training at each site were invited to the session, with the expectation that they would cascade training down to other staff at their local library. To help with this, workshop materials were offered to everyone in attendance so that they could run similar sessions for colleagues. Although InfoSkills team members offered to assist in training at each site, staff were encouraged to lead IWB training at their own libraries so that a sense of ownership of the technology would be developed at the local level. It is hoped that such delegation will lead to greater usage and adoption of the IWBs across all MMU libraries.

\footnotetext{
${ }^{2}$ MMU's IWBs are supplied by Promethean Ltd. For more information on Promethean go to: http://www.prometheanworld.com/uk/index.shtml
} 
Nevertheless, as certain obstacles to library-wide adoption of the IWBs were anticipated, the InfoSkills team developed measures to address these challenges. Some staff members who attended the training day were initially uneasy about the responsibility of training colleagues in the use of technology with which they were still relatively unfamiliar. To help them disseminate information to others and to reinforce their own learning, the InfoSkills team created a "Guide to ACTIVstudio2 and the Interactive Whiteboards", made available to all staff on the Library Intranet. Although there are comprehensive training guides available from the software supplier, the inhouse guides are more accessible and relevant to InfoSkills training. For further training and guidance, an INFORMS online guide ${ }^{3}$ with step-by-step instructions for using ACTIVstudio software was also created. This is intended for use at the desktop and allows staff to familiarise themselves with the software prior to delivering an InfoSkills session. Finally, a WIKI was set up on the Intranet providing an opportunity for staff to discuss experiences or difficulties and to share ideas across all library sites. It is also used to advertise future sessions using IWBs so staff can observe colleagues using them in a practical way.

Even after receiving training and practicing using the boards, a minority of staff were still not confident about using them in actual teaching sessions. The InfoSkills team acknowledged that for this reason adoption could be slow and encouraged staff to integrate IWBs into their classes incrementally at their own speed. A checklist of four competency levels was created covering basic functions, PowerPoint tools, Flipcharts, and advanced functions, each with a set of specific goals for incorporating IWBs into training sessions. These goals provide trainers with clear tasks to undertake in their sessions, which increase in difficulty and help build confidence as each new level is reached. By monitoring staff progress through their checklists, the InfoSkills team also has the opportunity to measure the ways in which IWBs have been used in the classroom and the degree to which they have been adopted. This

\footnotetext{
${ }^{3}$ To view the online guide go to: http://inhale.hud.ac.uk/perl/jump.pl?28-2255
} 
information will be used to produce statistics about IWB usage but all names will remain confidential.

It was anticipated that there would be a greater degree of unwillingness amongst staff to use IWBs than there has been. In fact, the IWBs seem to have encouraged staff to become more interactive in their training sessions. Where staff previously may have been reluctant to go beyond the safety of standard PowerPoint presentations and demonstrations, IWBs have become a vehicle for getting staff interested in experimenting in the classroom and engaging more with the audience. To this end, IWBs have actually helped build confidence in teaching.

Since reluctance to integrate the IWB in InfoSkills sessions has not occurred, progression with this new technology has been quicker than expected. Feedback from library sites has been positive and staff are becoming so comfortable with the boards that there now appears to be an unwillingness to teach without them. The InfoSkills team now needs to look to the future to ensure that the level of enthusiasm is maintained and that all new members of library staff are fully trained and continue to incorporate the IWB and its software into their sessions. As ownership of the technology is taken on by library staff, each site will be able to use the technology to suit their purposes and their environments. However, the InfoSkills team will need to continually be aware of how IWBs are being used across sites in order to gather examples of good practice. This will feed back into the development and enhancement of future materials. The team envisage that IWBs will become an integral part of MMU's InfoSkills teaching. With such positive adoption of IWBs and other initiatives, such as ACTIVote, MMU Library is showing itself to be a forerunner in embracing new learning technology. 


\section{References}

Becta (2004). ICT in schools survey 2004 [online]. London: DfES [accessed 21 March 2006]. Available at:

http://www.becta.org.uk/page documents/research/ict in schools survey 20 $\underline{\text { 04.pdf }}$

Philipp, S., and Schmidt, H. (2004). Optimizing learning and retention through interactive lecturing: using the Audience Response System (ARS) at CUMC [online]. Center for Education Research and Evaluation: Columbia University [accessed 28 January 2006]. Available at:

http://library.cpmc.columbia.edu/cere/web/facultydev/ARS handout 2004 ov erview.pdf

Promethean Ltd. (2004). Interactive Whiteboards: new tools, new pedagogies, new learning [online]. [accessed 2 February 2006]. Available at:

http://virtuallearning.org.uk/iwb/Views from practitioners.pdf

TechLearn (no date). Interactive whiteboards in education [online]. York:

Joint Information Systems Committee [accessed 2 February 2006]. Available at: http://www.jisc.ac.uk/uploaded documents/Interactivewhiteboards.pdf 